\title{
Novel Poly(urethane-amide)s from Polyurethane Prepolymer and Reactive Polyamide. Preparation and Properties
}

\author{
Tsutomu TAKeICHI, ${ }^{\dagger}$ Kyoko SuefujI, and Kazuto InOUE* \\ School of Materials Science, Toyohashi University of Technology, Tempaku-cho, Toyohashi 441-8580, Japan \\ ${ }^{*}$ Fukushima National College of Technology, Iwaki 970-8034, Japan
}

(Received January 30, 2002; Accepted April 22, 2002)

\begin{abstract}
A series of novel poly(urethane-amide)s were prepared by a reaction of a polyurethane (PU) prepolymer and a soluble polyamide (PA) containing aliphatic hydroxyl group in the backbone. PU prepolymer was prepared by a reaction of polyester polyol and 2,4-tolylenediisocyanate and then end-capped with phenol. Soluble PA was prepared by a reaction of 1-( $m$-aminophenyl)-2-( $p$-aminophenyl)ethanol and 4,4'-oxydibenzoyl chloride. PU prepolymer and PA were mixed in various weight ratios, and the blend solutions were cast on glass substrates. The cast films were thermally treated at various temperatures, which allowed the release of phenol. The regenerated isocyanate group in the PU prepolymer reacted with hydroxyl group in the PA, giving a series of white opaque poly(urethane-amide) films. By changing the ratio of PU and PA, poly(urethane-amide) films having various properties from plastic to elastomer were prepared. Dynamic mechanical analysis showed two glass transition temperatures, one for the PU component at lower temperature range and the other for the PA component at higher temperature range, suggesting that the two polymer components were phase separated. When PU component was more than $80 \mathrm{wt} \%$, the films had the properties of elastomer. The rubbery plateaus region of the storage modulus for the elastic films was broad and continued up to $c a .200^{\circ} \mathrm{C}$. Tensile measurements showed that the elongation was $326 \%$ for the elastic film of PU/PA $=90 / 10$. Thermogravimetric analyses indicated that the thermal degradation of poly(urethane-amide) occurs at $c a .280^{\circ} \mathrm{C}$. These indicated that the introduction of PA component containing aliphatic alcohol in the backbone improved the thermal properties, and thus enhanced the use temperature of PU.
\end{abstract}

KEY WORDS Poly(urethane-amide)/ Polyurethane Prepolymer/ Soluble Polyamide / Aliphatic Alcohol / Elastomer / Thermal Properties /

Polyurethane (PU) is a versatile polymer and is becoming increasingly important as engineering materials, because it can be easily prepared by a simple polyaddition reaction of polyol, isocyanate and chain extender, and also because the tailor-made properties from supersoft flexible foam to tough elastomers and long-wearing coatings have resulted in many end applications. PU also has excellent abrasion resistance and properties of both elastomer and plastics. ${ }^{1-4}$ Unfortunately, the conventional PU is known to exhibit poor thermal stability, which limits its applications in harsh conditions. For example, the acceptable mechanical properties disappear above $80-90^{\circ} \mathrm{C}$ and thermal degradation takes place at temperatures above $200^{\circ} \mathrm{C} .^{5}$

Attempts to improve the thermal stability of PU have been made over a long period. One method is the chemical modification of its structure by blending or copolymerizing with more thermally stable polymers. Some of these examples are poly(urethaneurea), ${ }^{6,7}$ poly(urethane-epoxy), ${ }^{8-10}$ and poly(urethanediacetylene). ${ }^{11}$ Recently, aromatic polymers have been paid more attention for the modification. Aromatic polyimides and polyamides are an important class of aromatic polymers with remarkable heat resistance and superior mechanical, electrical, and durable properties. $^{12,13}$ Various attempts to incorporate polyimide units into PU have been made. Reaction of isocyanateterminated PU prepolymer with acid dianhydride monomer is the method most often utilized to introduce the imide function into the PU backbone. ${ }^{14-17}$ A modified method was also utilized, in which an acid dianhydride was reacted with aminoethanol to give hydroxyl-terminated imide monomer, which was then reacted with isocyanate-terminated PU prepolymer. ${ }^{18}$ Another modified method is the reaction of isocyanate-terminated PU prepolymer with aromatic diamine and dianhydride to prepare PU with imide groups in the backbone. ${ }^{19}$ Poly(urethane-imide)s obtained by these methods are linear, which should results in poor solvent-resistance to ordinary organic solvents.

Very recently, we reported a novel approach to prepare a series of poly(urethane-imide)s. Our approach is based on the reaction between PU prepolymer and poly(amide acid), which is a precursor of polyimide. ${ }^{2,21}$ The prepared poly(urethane-imide)s have network structure and showed improved thermal stability and excellent solvent-resistance. The poly(urethaneimide) films were plastic or elastomer depending on

${ }^{\dagger}$ To whom correspondence should be addressed (Tel: +81-532-44-6815, Fax: +81-532-48-5833, E-mail: takeichi@tutms.tut.ac.jp). 
the ratio of the two components. The formation of urethane-imide linkage in the novel method is based on the reaction between in-situ generated isocyanate group in the PU prepolymer and carboxylic group in the poly(amide acid). The reaction of poly(amide acid) with PU prepolymer, however, occurs at similar temperature range with the imidization of poly(amide acid), and the structure of the poly(urethane-imide) cannot be well-defined.

Thus we examined another novel approach, which is based on the reaction between terminal isocyanates in the PU prepolymer and pendent phenolic hydroxyl groups in the soluble polyimides. ${ }^{22}$ We also examined the reaction between terminal isocyanates in the PU prepolymer and in-situ formed phenolic hydroxyl groups in the polybenzoxazine. ${ }^{23,24}$ Both approach successfully prepared PU elastomers with improved thermal properties. However, the urethane linkage formed from the reaction between phenolic hydroxyl group and isocyanate dissociate at $c a .120^{\circ} \mathrm{C}-150^{\circ} \mathrm{C}$, and the use temperature of the films estimated from the viscoelastic measurement was $c a .150^{\circ} \mathrm{C}$. It is known that the urethane linkage from the reaction between aliphatic hydroxyl group and isocyanate dissociates at ca. $250^{\circ} \mathrm{C}$, much higher than the urethane linkage from phenolic hydroxyl group and isocyanate. This leads to the expectation that the reaction of aliphatic hydroxyl group in an aromatic polymer and isocyanteterminated PU prepolymer will afford modified PU that can be used up to higher temperatures. Aiming to improve the high temperature properties of $\mathrm{PU}$, we report here our novel approach for preparing a novel type of poly(urethane-amide)s by the reaction between isocyanate in PU prepolymer and aliphatic hydroxyl group in aromatic polyamide (PA).

\section{EXPERIMENTAL}

\section{Reagents}

Polyethyleneadipate polyol with molecular weight of 1000 (OH number in KOH: 113), delivered by Nippon Polyurethane Ltd. as Nippollan 4002, was dehydrated in vacuo at $80^{\circ} \mathrm{C}$ for one night before use. Tolylene-2,4-diisocyanate (TDI) was used as received from Nippon Polyurethane Ltd. 4,4'-Oxydibenzoyl chloride (ODB) was obtained from Tokyo Kasei, Japan. 1-(m-Aminophenyl)-2-( $p$-aminophenyl)ethanol $(\alpha-\mathrm{OH})$ was prepared according to the previously reported method. ${ }^{25}$ Phenol was used as received from Kishida Chemical Co. $N$-Methyl-2-pyrrolidone (NMP) and $N, N$-dimethylacetamide (DMAc) obtained from Kishida Chemical Co., were purified by distillation under reduced pressure.

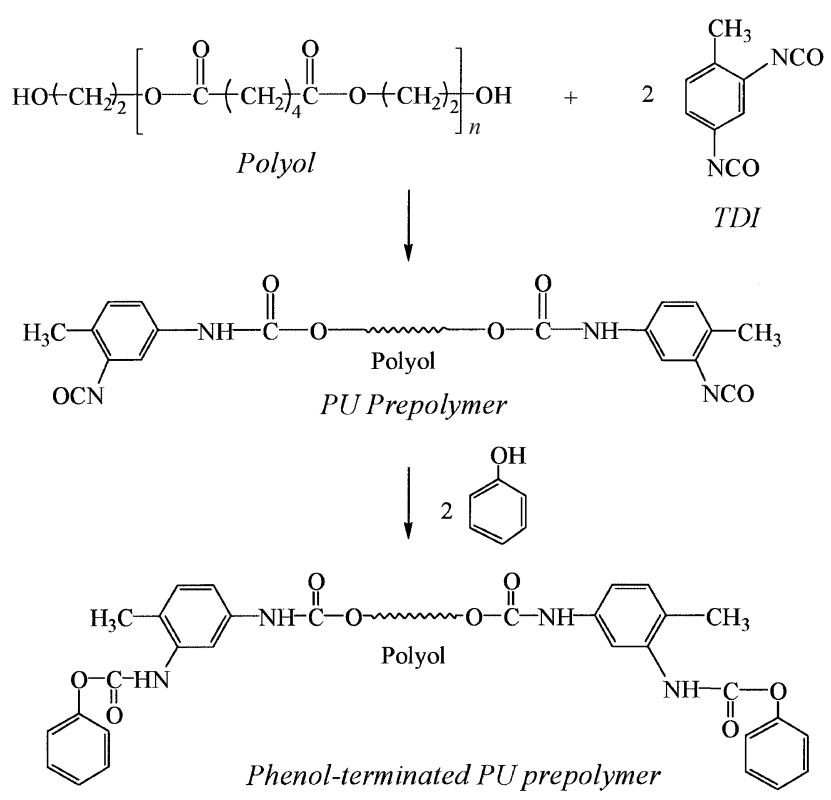

Scheme 1. Preparation of PU prepolymer.

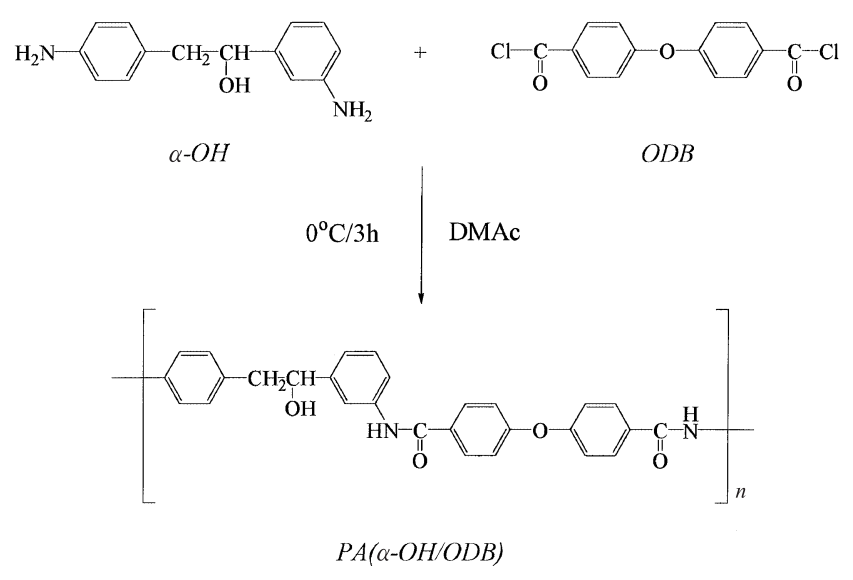

Scheme 2. Preparation of PA ( $\alpha-\mathrm{OH} / \mathrm{ODB})$.

\section{Preparation of PU Prepolymer}

PU prepolymer was prepared following the Scheme 1. TDI $(20 \mathrm{mmol}, 3.58 \mathrm{~g})$ was added into dehydrated polyethylene adipate $(10 \mathrm{mmol}, 10.00 \mathrm{~g})$, and reacted at $80^{\circ} \mathrm{C}$ for $2 \mathrm{~h}$ under nitrogen atmosphere to give PU prepolymer as a viscous liquid. Phenol $(20.4 \mathrm{mmol}, 1.92 \mathrm{~g})$ was then added into the liquid and reacted at $80^{\circ} \mathrm{C}$ for $3 \mathrm{~h}$ to give PU prepolymer end-capped with phenol. The liquid was diluted with $16.35 \mathrm{~g}$ of NMP to give a $50 \%$ PU prepolymer solution.

\section{Preparation of $P A(\alpha-O H / O D B)$}

PA was prepared by the reaction of an equimolar amount of $\alpha-\mathrm{OH}$ and ODB in NMP as shown in Scheme 2. $\alpha$-OH (10.00 mmol, $2.283 \mathrm{~g})$ was dissolved in DMAc $(10 \%, 38.82 \mathrm{~g})$ under a nitrogen atmosphere. An equimolar amount of ODB $(10.00 \mathrm{mmol}, 2.790 \mathrm{~g})$ was added, followed by stirring at $0^{\circ} \mathrm{C}$ for $3 \mathrm{~h}$, and then the reaction mixture was poured into $1.2 \mathrm{~L}$ of water. 
The obtained white PA flake powder was vacuum filtered, washed with $5 \mathrm{~L}$ of water, and then dried in vacuo for one night. The yield of the PA was $97-98 \%$. Viscosity of the PA was $0.490-0.520 \mathrm{dL} \mathrm{g}^{-1}$ at the concentration of $0.5 \mathrm{~g} \mathrm{dL}^{-1}$ in DMAc.

\section{Preparation of Poly(urethane-amide)}

$\mathrm{PA}(\alpha-\mathrm{OH} / \mathrm{ODB})$ was dissolved in NMP to give a $10 \%$ solution. Then, PA solution and PU prepolymer solution were mixed at various weight ratios $(\mathrm{PU} / \mathrm{PA}=$ $0 / 100,20 / 80,50 / 50,80 / 20,85 / 15,90 / 10)$. The blend solutions were cast on glass plates, and solvent was evaporated under vacuum at $50^{\circ} \mathrm{C}$ for $16 \mathrm{~h}$. The cast films were then thermally treated at $100^{\circ} \mathrm{C}$ and $200^{\circ} \mathrm{C}$ for $1 \mathrm{~h}$ each.

\section{Measurements}

Viscosity of PA was measured using Ubbelohde viscometer at a concentration of $0.5 \mathrm{~g} \mathrm{dL}^{-1}$ in DMAc at $30^{\circ} \mathrm{C}$. IR was measured using JEOL Model IR 810. Differential scanning calorimetry (DSC) was performed with a Rigaku Thermo Plus 2 DSC8230. Samples of $c a .10 \mathrm{mg}$ in weight were heated from 30 to $500^{\circ} \mathrm{C}$ at a heating rate of $10^{\circ} \mathrm{C} \mathrm{min}{ }^{-1}$ under nitrogen. Thermogravimetric analyses (TGA) were carried out with a Rigaku Thermo Plus 2 TG-DTA TG8120. Samples of $c a .10 \mathrm{mg}$ in weight were heated from 30 to $850^{\circ} \mathrm{C}$ at a heating rate of $5^{\circ} \mathrm{C} \mathrm{min}^{-1}$ under Ar. Dynamic viscoelastic measurements were performed using Orientec Automatic Viscoelastometer Rheovibron Model DDV-01FP from -80 to $400^{\circ} \mathrm{C}$ at $35 \mathrm{~Hz}$ at a heating rate of $4{ }^{\circ} \mathrm{C} \mathrm{min}^{-1}$. Tensile properties were investigated using an IMADA Seisaku-sho Model SV-3 at room temperature. Sample lengths were $c a .2 \mathrm{~cm}$, widths were $c a .3 \mathrm{~mm}$ and crosshead speed was $1 \mathrm{~cm}$ $\min ^{-1}$.

\section{RESULTS AND DISCUSSION}

\section{Preparation of Poly(urethane-amide) Films}

We intended to prepare a series of novel poly(urethane-amide)s by a simple reaction between aliphatic hydroxyl groups in a PA and terminal isocyanates in a PU prepolymer. For that propose, we prepared a soluble PA having aliphatic hydroxyl groups from the reaction between $\alpha-\mathrm{OH}$, a diamine that contains aliphatic hydroxyl group, and ODB, a diacid chloride that contains flexible ether. $\mathrm{PA}(\alpha-\mathrm{OH} / \mathrm{ODB})$ was readily soluble in various organic solvents such as DMF and NMP as shown in Table I. PA $(\alpha-\mathrm{OH} / \mathrm{ODB})$ gave pale-yellow, transparent tough films.

PU prepolymer solution and PA solution were mixed in various weight ratios according to the formula-
Table I. Solubility of $\mathrm{PA}(\alpha-\mathrm{OH} / \mathrm{ODB})$

\begin{tabular}{|c|c|}
\hline Solvent & Solubility $^{\mathrm{a}}$ \\
\hline$N, N$-Dimethylacetamide & +++ \\
\hline$N, N$-Dimethylformamide & +++ \\
\hline$N$-Methyl-2-pyrrolidone & +++ \\
\hline Dimethyl sulfoxide & +++ \\
\hline Pyridine & +++ \\
\hline$m$-Cresol & ++ \\
\hline Methanesulfonic acid & +++ \\
\hline Sulfuric acid & + \\
\hline Tetrahydrofuran & + \\
\hline Formic acid & - \\
\hline Chloroform & - \\
\hline Ethanol & - \\
\hline
\end{tabular}

Table II. Formulation of Poly(urethane-amide)s

\begin{tabular}{|c|c|c|}
\hline$\frac{\text { PU/PA ratio }}{w^{0} / 0}$ & $\frac{\text { PU/PA ratio }}{\sigma}$ & $\begin{array}{c}\text { Film } \\
\text { characteristics }\end{array}$ \\
\hline $100 / 0$ & $1.000 / 0.000$ & Elastic \\
\hline $90 / 10$ & $0.450 / 0.050$ & Elastic \\
\hline $85 / 15$ & $0.283 / 0.050$ & Elastic \\
\hline $80 / 20$ & $0.200 / 0.050$ & Elastic \\
\hline $50 / 50$ & $0.050 / 0.050$ & Plastic \\
\hline $20 / 80$ & $0.013 / 0.050$ & Plastic \\
\hline $0 / 100$ & $0.000 / 0.050$ & Plastic \\
\hline
\end{tabular}

tion shown in Table II. The addition of isocyanateterminated PU prepolymer into soluble PA caused gelation as a result of the formation of network. In order to prevent gelation during mixing, isocyanate groups were protected with phenol. All the blend solutions were clear and transparent at any weight ratios. Films were cast on glass plates from the solution. After drying, the cast films became opaque, which indicates that phase separation occurred between the two components. During the heat treatment of the cast films at $200^{\circ} \mathrm{C}$ in vacuo, end-capped phenol was released to regenerate NCO. The splitting reaction of phenol from PU prepolymer was confirmed to occur at $120^{\circ} \mathrm{C}$ by DSC and TGA. ${ }^{20}$ The isocyanate groups that were generated by the removal of phenol reacted with hydroxyl groups in the PA, giving poly(urethane-amide). The reaction between PU prepolymer and hydroxyl groups in the PA occurs at the interface of separated phase. All the PU/PA films were white colored and opaque, and the transparency decreased with the increase of PU content. The films with less than $50 \%$ of PU content were plastic, and the films with more than $80 \%$ of PU were elastic.

The progress of the reaction was followed using IR. As shown in Figure 1a, IR spectrum for the pure PA showed a broad absorption at $3100-3500 \mathrm{~cm}^{-1}$ based on the stretching modes of $\mathrm{O}-\mathrm{H}$ and of $\mathrm{N}-\mathrm{H}$. Ab- 


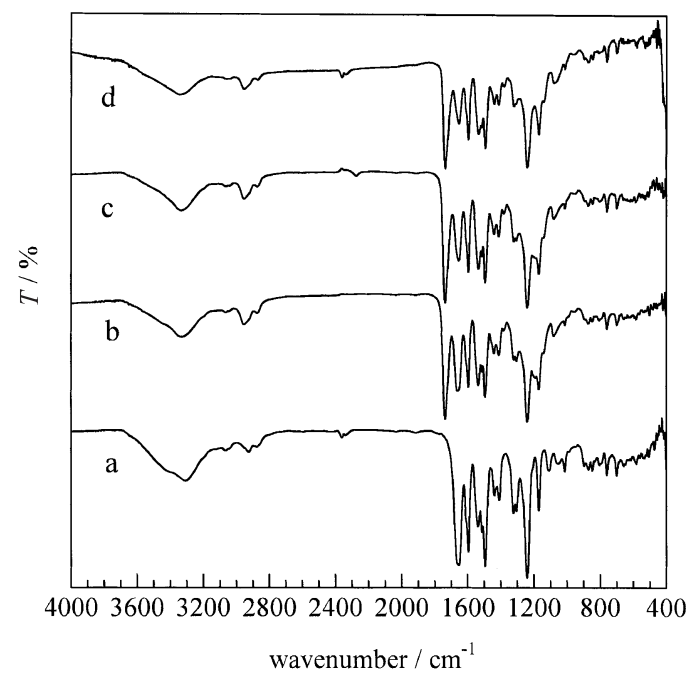

Figure 1. IR spectra of $\mathrm{PA}(\alpha-\mathrm{OH} / \mathrm{ODB})$ and poly(urethaneamide), $\mathrm{PU} / \mathrm{PA}=50 / 50$, treated at various temperatures. $\mathrm{PA}(\alpha-$ $\mathrm{OH} / \mathrm{ODB}) \mathrm{a}$ ), poly(urethane-amide) treated at $\left.50^{\circ} \mathrm{C} \mathrm{b}\right), 100^{\circ} \mathrm{C} \mathrm{c}$ ), and $200^{\circ} \mathrm{C} \mathrm{d}$ ).

sorptions due to the $\mathrm{C}-\mathrm{H}$, carbonyl of amide $\mathrm{I}$, and aromatic ring appeared at $2900 \mathrm{~cm}^{-1}, 1654 \mathrm{~cm}^{-1}$, and $1600 \mathrm{~cm}^{-1}$, respectively. Figure 1 also shows the change of IR of poly(urethane-amide) after various heat treatments. In Figure 1b, the absorption of ester group is observed at $1750 \mathrm{~cm}^{-1}$, and of methylene at $2950 \mathrm{~cm}^{-1}$. After the heat treatment at $100^{\circ} \mathrm{C}$ (Figure 1c), the characteristic absorption of NCO appeared slightly at $2270 \mathrm{~cm}^{-1}$. It indicates that phenol splitted from $\mathrm{PU}$ prepolymer, regenerating reactive $\mathrm{NCO}$ which react with hydroxyl group in the PA. The absorption disappeared completely after the $200^{\circ} \mathrm{C}$ treatment (Figure 1d), showing that the reaction was completed to afford poly(urethane-amide).

\section{Viscoelastic Properties of Poly(urethane-amide) Films}

Dynamic mechanical analysis of poly(urethaneamide) films are shown in Figures 2 and 3. Two glass transition temperatures $\left(T_{\mathrm{g}}\right)$ appeared for the films of $\mathrm{PU} / \mathrm{PA}=20 / 80$ and $50 / 50$. The lower $T_{\mathrm{g}}$ is due to the PU component and the higher $T_{\mathrm{g}}$ to the PA component, suggesting that the polymer components are phase separated. Alloying with PU shifted the $T_{\mathrm{g}}$ value of PA to lower temperature range from $241^{\circ} \mathrm{C}$ of pristine PA to $181-186^{\circ} \mathrm{C}$. This suggests some miscibility between PU and PA components. In the elastomer films, as shown in Figure 3, a wide rubbery plateau region appeared for storage modulus up to $c a .180^{\circ} \mathrm{C}$ at which $T_{\mathrm{g}}$ of PA appeared. In the previous poly(urethane-imide) films prepared from phenolic hydroxyl group and PU prepolymer, the rubbery plateau region continued up to $c a .150^{\circ} \mathrm{C}^{22}$ Thus it was clearly shown that, by forming urethane linkage between the PU prepolymer and

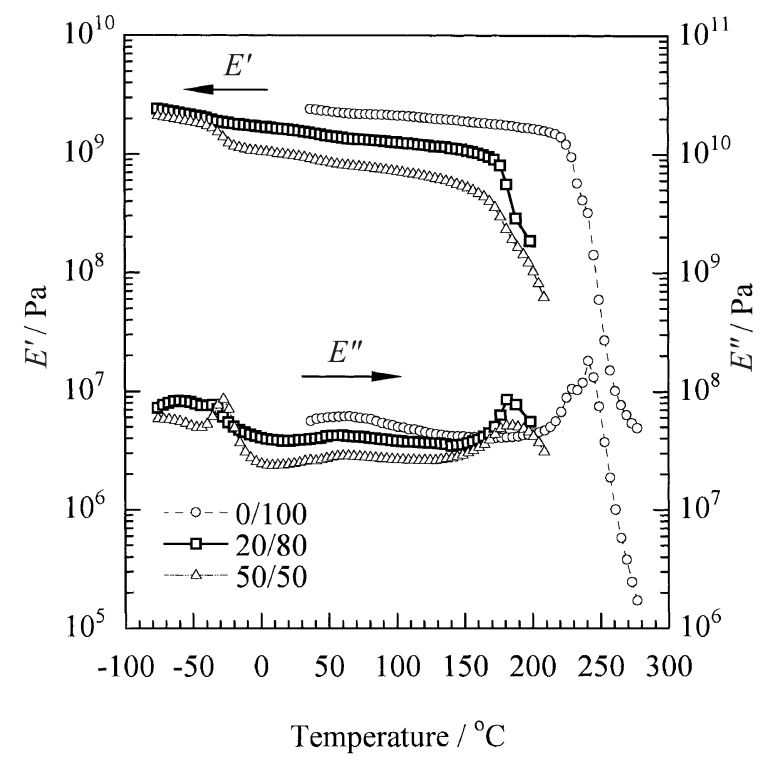

Figure 2. Viscoelastic properties of poly(urethane-amide) films.

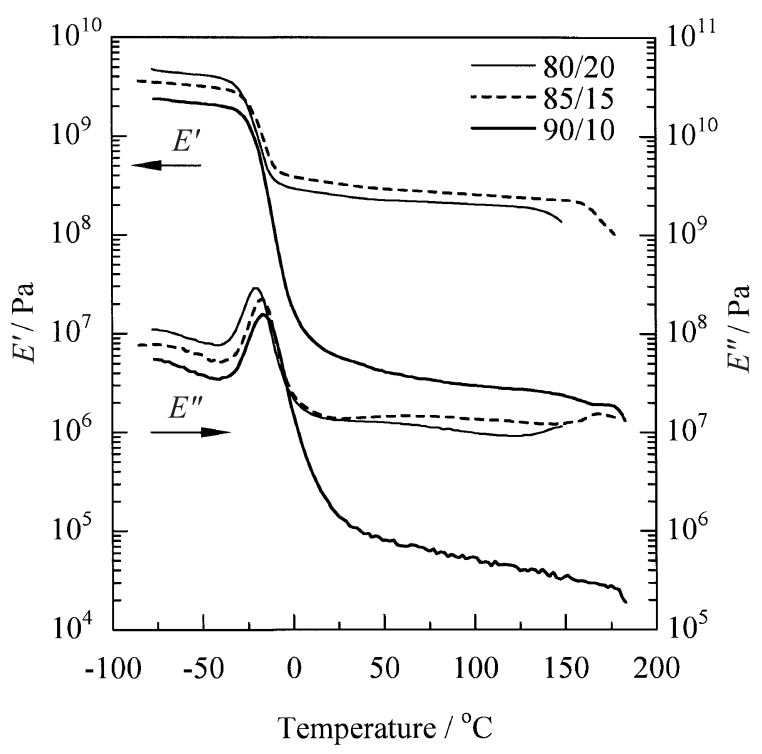

Figure 3. Viscoelastic properties of poly(urethane-amide) films.

aliphatic hydroxyl group, the use temperature of PU elastomers was enhanced up to higher temperature than the urethane linkage between the PU prepolymer and phenolic hydroxyl group. Though remarkable increase of use temperature of PU was not achieved by the alloying with the PA used in this study, it was clearly shown that the use temperature was limited by the $T_{\mathrm{g}}$ of PA. The results lead to the conclusion that the use of PA with higher $T_{\mathrm{g}}$ should afford modified PU with much increased use temperature.

\section{Tensile Properties of Poly(urethane-amide) Films}

Tensile properties of poly(urethane-amide) films are summarized in Table III. The tensile modulus, tensile strength, and elongation at break of the pristine 
Table III. Tensile Properties of Poly(urethane-amide) films

\begin{tabular}{|c|c|c|c|}
\hline$\frac{\text { PU/PA ratio }}{w^{\circ} \%}$ & $\frac{E}{\mathrm{GPa}}$ & $\frac{\sigma}{\mathrm{MPa}}$ & $\frac{\text { Elongation }}{\%}$ \\
\hline $0 / 100$ & 1.93 & 51.4 & 7.8 \\
\hline $20 / 80$ & 0.88 & 20.2 & 6.4 \\
\hline $50 / 50$ & 0.78 & 17.7 & 4.4 \\
\hline $80 / 20$ & $48 \times 10^{-3}$ & 0.96 & 75 \\
\hline $90 / 10$ & $2.2 \times 10^{-3}$ & 2.25 & 326 \\
\hline
\end{tabular}

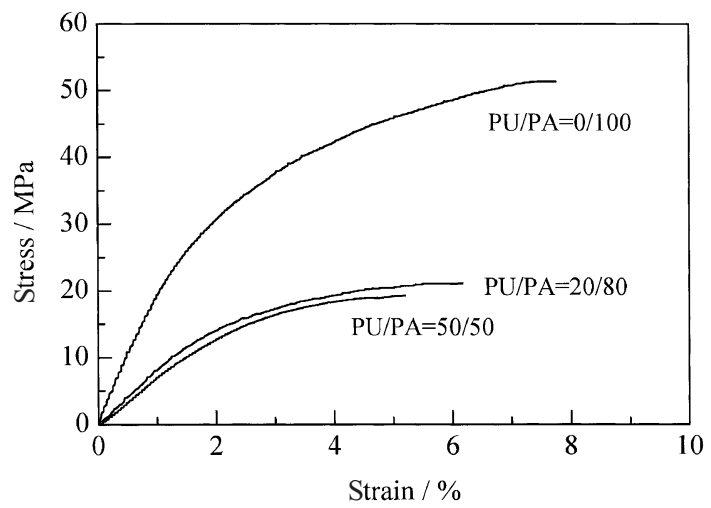

Figure 4. Typical stress-strain curves for the plastic films of poly(urethane-amide).

PA were $1.9 \mathrm{GPa}, 48 \mathrm{MPa}$, and $8 \%$, respectively. The poly(urethane-amide) films showed various properties depending on the ratio of PU and PA components. When PU component was less than $50 \mathrm{wt} \%$, the films had the properties of plastics. Typical stress-strain curves for the plastic films are shown in Figure 4. The initial tensile modulus of these plastic films was lowered to $c a .0 .8 \mathrm{GPa}$ from the $1.9 \mathrm{GPa}$ of pristine PA. Tensile strength for plastic films was $c a .20 \mathrm{MPa}$, and elongation was $c a$. under $10 \%$.

Typical stress-strain curves for the elastomer films are shown in Figure 5. The elongation was 326\% for the film of PU/PA $=90 / 10$. The initial modulus and tensile strength for the film were $2.21 \mathrm{MPa}$ and $2.25 \mathrm{MPa}$, respectively, and the stress-strain curve showed typical pattern of elastomer. Though the films of PU/PA $=80 / 20$ was elastomer, elongation at break was not so high, probably due to the heterogeneity apparent in the film. From the similarity of morphology previously studied in the case of poly(urethane-imide) films, ${ }^{26}$ it is considered that PA forms continuous phase with PU domains in the plastic films, and PU forms continuous phase in the elastomer films. Poor performance of the elastomeric poly(urethane-amide) films of PU/PA = $80 / 20$ suggests that phase inversion is taking place at the ratio very near to $\mathrm{PU} / \mathrm{PA}=80 / 20$.

\section{Thermal Stability of Poly(urethane-amide)s}

Thermogravimetric analyses (TGA) of poly(urethaneamide)s along with pristine PA are shown in Figure 6.

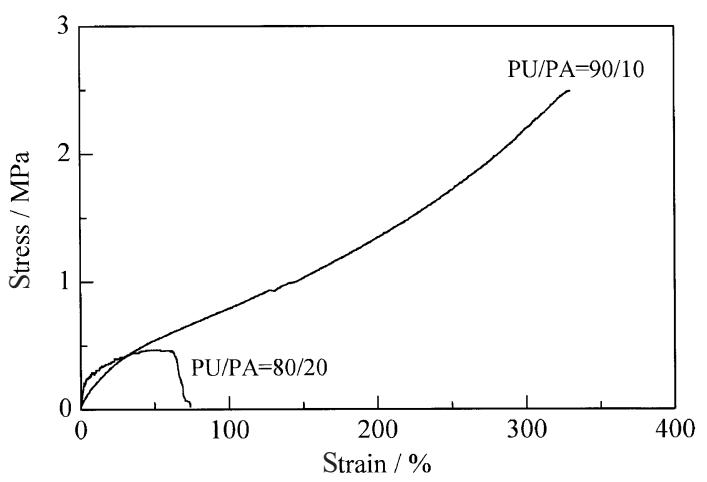

Figure 5. Typical stress-strain curves for the elastic films of poly(urethane-amide).

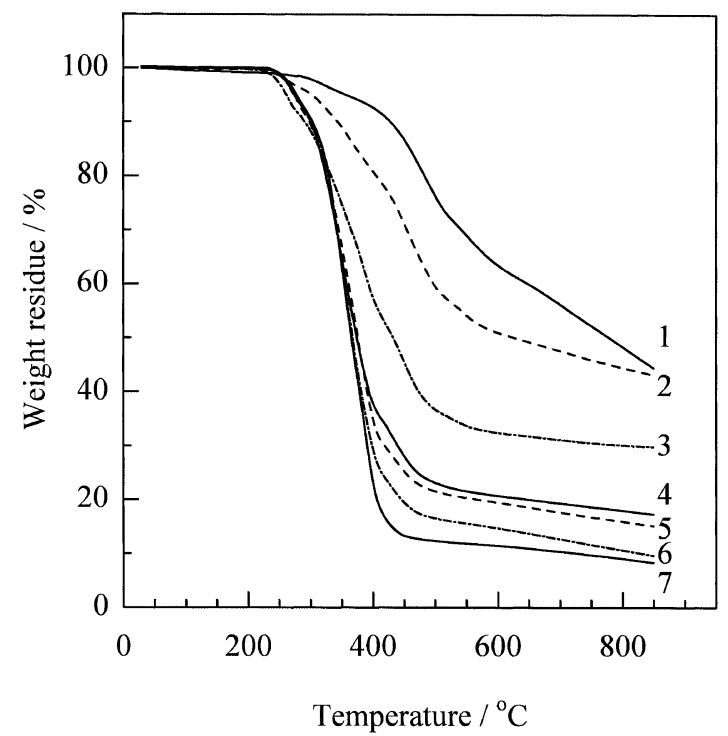

Figure 6. TGA of poly(urethane-amide)s. 1. PU/PA $=0 / 100$; 2. $\mathrm{PU} / \mathrm{PA}=20 / 80 ; 3$. $\mathrm{PU} / \mathrm{PA}=50 / 50 ; 4 . \mathrm{PU} / \mathrm{PA}=80 / 20 ; 5$. $\mathrm{PU} / \mathrm{PA}$ $=85 / 15 ; 6 . \mathrm{PU} / \mathrm{PA}=90 / 10 ; 7 . \mathrm{PU} / \mathrm{PA}=100 / 0$.

For the pure PA containing aliphatic alcohol, degradation occurred in two stages. The initial decomposition temperature as $5 \%$ weight loss was $359^{\circ} \mathrm{C}$ which is considered to result from the degradation of hydroxyl groups, and the second stage appeared above $420^{\circ} \mathrm{C}$ due to the degradation of amide backbone. TGA for poly(urethane-amide)s also showed two degradation stages, and the initial decomposition temperatures as $5 \%$ weight loss was about $280^{\circ} \mathrm{C}$. The introduction of relatively thermally labile PA component did not enhance the thermal stability of PU so much, but thermal stability was high enough to keep the rubber property up to $c a .200^{\circ} \mathrm{C}$.

\section{CONCLUSIONS}

A series of poly(urethane-amide) films were successfully prepared by the reaction of PU prepolymer and aromatic PA which have aliphatic hydroxyl group. By changing the ratio of PU and PA components, 
Table IV. TGA of Poly(urethane-amide)s

\begin{tabular}{|c|c|c|}
\hline PU/PA & $5 \%$ loss & $10 \%$ loss \\
\hline wt $\%$ & ${ }^{\circ} \mathrm{C}$ & ${ }^{\circ} \mathrm{C}$ \\
\hline $0 / 100$ & 359 & 430 \\
\hline 20/80 & 304 & 345 \\
\hline $50 / 50$ & 262 & 292 \\
\hline $80 / 20$ & 275 & 301 \\
\hline $90 / 10$ & 277 & 301 \\
\hline $100 / 0$ & 278 & 299 \\
\hline
\end{tabular}

poly(urethane-amide) films having various properties from plastic to elastomer were prepared. The PU and PA components were phase separated. When PU component was more than $80 \mathrm{wt} \%$, the films had the properties of elastomer. The wide rubbery plateaus region of the storage modulus of the elastomer films were continued up to $c a \cdot 200^{\circ} \mathrm{C}$. Tensile measurement of the elastic films showed that the elongation was $326 \%$ in the case of PU/PA $=90 / 10$. TGA indicated that the thermal degradation of poly(urethane-amide) occurred at ca. $280^{\circ} \mathrm{C}$. These indicated that the urethane linkage formed from aliphatic hydroxyl group in the PA backbone and NCO in PU prepolymer enhanced the use temperature of $\mathrm{PU}$ than that from phenolic hydroxyl group in the aromatic polymer and $\mathrm{NCO}$ of PU prepolymer. Since the use temperature is limited by the glass transition temperature of the PA employed for the alloying, the use of PA or other reactive polymers having higher glass transition temperatures should further enhance the use temperature of PU. The research is currently under way.

\section{REFERENCES}

1. K. Iwata, in "Handbook of Polyurethane Resins", K. Iwata, Ed., The Nikkan Kogyo Shimbun Ltd., Japan, 1987, chapt. 1.

2. J. H. Saunders and K. C. Frisch, in "Polyurethane; Part I Chemistry", Interscience, New York, N.Y., 1962, chapt. 6.

3. M. J. Comstock, in "Urethane Chemistry and Applications", ACS Symposium Series No. 172, Washington, D.C. 1981, chapt. 1 .
4. N. R. Legge, G. Holden, and H. E. Schroeder, "Thermoplastic Elastomers", W. Meckel, W. Goyert, and W. Wieder, Ed., Carl Hanser Verlag, Munich, Vienna, New York, 1987, chapt. 2.

5. H. J. Fabris, in "Advance in Urethane Sci. and Tech.", Technomic Publishing Co., Westport, CT, 1976, p 89.

6. N. Yui, K. Nojima, K. Sanui, and N. Ogata, Polym. J., 17, 969 (1985).

7. O. Matsuda, Y. Taniguchi, and J. Soejima, JP Patent H 08217849 (Aug. 27, 1996).

8. T. H. Ho and C. S. Wang, Polymer, 37, 2733 (1996).

9. B. G. Barron, S. H. Dai, and J. R. Porter, U. S. Patent 5525 681 (June 11, 1996).

10. W. T. Wu, H. W. Tai, and L. C. Zhang, Hebei Gongye Daxue Xuebao, 25, 16 (1996).

11. M. F. Rubner, Macromolecules, 19, 2114 (1986).

12. M. K. Ghosh and K. L. Mittal, Eds., "Polyimide: Fundamentals and Applications", Marcel Dekker, Inc., New York, N.Y., 1996.

13. C. Feger, M. M. Khojasteh, and S. E. Molis, Eds., "Polyimides: Trends in Materials and Applications", Society of Plastics Engineers, Mid Hudson Section, Society of Plastics Engineers, Inc., Hopewell Junction, New York, N.Y., 1996.

14. A. Sendijarevic, V. Sendijarevic, and K. C. Frisch, J. Polym. Sci., Part A: Polym. Chem., 28, 3603 (1990).

15. W. J. Bailey, J. Economy, and M. E. Hermas, J. Org. Chem., 27, 3295 (1962).

16. D. C. Liao and K. H. Heieh, J. Polym. Sci., Part A: Polym. Chem., 32, 1665 (1994).

17. H. Cheng, C. Yue, and X. Xu, Gaofenzi Cailiao Kexue Yu Gongcheng, 5, 79 (1989).

18. R. Matsuo and A. Niki, JP Patent H 07-330856 (Dec. 19, 1995).

19. E. Radlmann, A. Köhler, and G. Nischk, German Patent DE 2 017511 (Dec. 23, 1971).

20. M. Zuo and T. Takeichi, J. Polym. Sci., Part A: Polym. Chem., 35, 3745 (1997).

21. M. Zuo, Q. Xiang, and T. Takeichi, Polymer, 39, 6883 (1998).

22. M. Zuo, T. Takeichi, Polymer, 40, 5153 (1999).

23. T. Takeichi, Y. Guo, and T. Agag, J. Polym. Sci., Part A: Polym. Chem., 38, 4165 (2000).

24. T. Takeichi and Y. Guo, Polym. J., 33, 437 (2001).

25. K. Inoue and Y. Imai, Proceedings of International Symposium on Condensation Polymers, Yonezawa, 1995, p 83.

26. T. Takeichi, T. Kawai, and H. Tsuchiya, High Perform. Polym., 13, 159 (2001). 